\title{
Cathodoluminescence of Double Layers of Phosphor Particles
}

\author{
Daniel den Engelsen, Paul Harris, Terry Ireland, ${ }^{\mathrm{Z}}$ and Jack Silver ${ }^{\mathrm{Z}}$
}

Centre for Phosphor and Display Materials, Wolfson Centre for Materials Processing, Brunel University, Uxbridge, Middlesex UB8 3PH, United Kingdom

\begin{abstract}
We present radiance measurements of particle layers of $\mathrm{ZnO}: \mathrm{Zn}, \mathrm{Y}_{2} \mathrm{O}_{3}: \mathrm{Eu}$ and $\mathrm{Y}_{2} \mathrm{O}_{2} \mathrm{~S}$ :Eu bombarded with electrons at anode voltages between 1 and $15 \mathrm{kV}$. The layers described in this work refer to single component layers, double layers and two component mixtures. The phosphor layers are deposited on ITO-coated glass slides by settling; the efficiency of the cathodoluminescence is determined by summing the radiances and luminances in the reflected and transmitted modes respectively. The efficiency of a double layer of $\mathrm{Y}_{2} \mathrm{O}_{3}: \mathrm{Eu}$ on top of $\mathrm{ZnO}: \mathrm{Zn}$ at high electron energy is significantly larger than the efficiency of a corresponding layer in which the two components are mixed. This result is interpreted in terms of the penetration-model, which predicts a larger efficiency for a high-voltage phosphor on top of a low-voltage phosphor. When a layer of the low-voltage phosphor $\mathrm{ZnO} \mathrm{Zn}$ is on top of the high-voltage phosphor $\mathrm{Y}_{2} \mathrm{O}_{3}: \mathrm{Eu}$, we also observe a higher efficiency than that of the corresponding layer with both components mixed. In this case the efficiency increases due to suppression of charging in the $\mathrm{Y}_{2} \mathrm{O}_{3}$ :Eu layer. Double layers of $\mathrm{ZnO}: \mathrm{Zn}$ and $\mathrm{Y}_{2} \mathrm{O}_{2} \mathrm{~S}$ :Eu did not show enhanced efficiency, because the size of the $\mathrm{Y}_{2} \mathrm{O}_{2} \mathrm{~S}$ : Eu particles was too large to evoke the penetration effect. (C) The Author(s) 2014. Published by ECS. This is an open access article distributed under the terms of the Creative Commons Attribution 4.0 License (CC BY, http://creativecommons.org/licenses/by/4.0/), which permits unrestricted reuse of the work in any medium, provided the original work is properly cited. [DOI: 10.1149/2.021404jss] All rights reserved.
\end{abstract}

Manuscript submitted January 20, 2014; revised manuscript received February 12, 2014. Published February $22,2014$.

Recently we have described an idea to enhance the efficiency of cathodoluminescence (CL) of phosphor particle layers by depositing one layer on top of another. ${ }^{1}$ Such an enhancement is to be expected when a high-voltage phosphor is deposited on top of a low-voltage phosphor. The difference between a high- and low-voltage phosphor is the light output at low electron beam energies: a low-voltage phosphor has a high luminance yield, whilst the luminance of a high-voltage phosphor is low. At higher voltages, however, the high-voltage phosphor has the greatest output. As primary electrons penetrate the phosphor they progressively lose energy until they can no longer excite the phosphor. When the top, high-voltage, layer is thin enough to allow electrons of sufficient energy (but not enough to excite the high energy one) to penetrate into the low-voltage phosphor layer enhancement of the luminance may be expected. We shall refer to this theory as the "penetration model".

An application of electron penetration in double and multi layers of phosphors were so-called "penetrons": Penetration CRTs, in which the color of the cathodoluminescence could be tuned by changing the energy of the electron beam. ${ }^{2-4}$ The objective of the scientists who developed penetrons was to maximize the color gamut of the tubes; no attention was paid to enhancing the lumen output.

If the energy of the electron beam is not high enough, the electrons do not pass through the top layer and there will be no enhancement of the luminance. This was the main reason that there was no observable increase of the lumen efficacy of a thin layer of nano-sized $\mathrm{Y}_{2} \mathrm{O}_{3}: \mathrm{Eu}$ particles on top of a $\mathrm{ZnO}$ : $\mathrm{Zn}$ layer using electron beam energies up to $5 \mathrm{Kv} .{ }^{1}$ Another reason was the charging of non-conducting $\mathrm{Y}_{2} \mathrm{O}_{3}$ :Eu layers upon electron bombardment. In order to cope with the charging of phosphor layers the measuring method was modified. Recently we published a new measuring method (the "comparison method") to determine the CL of an insulating phosphor layer. ${ }^{5}$ The objective of the work described here, was to investigate the effect of double layers of phosphor particles on the lumen and energy efficiency by using electron beam energies up to $15 \mathrm{kV}$ and applying the comparison measuring method.

The underlying motive to study the effect of double and multi layers of phosphor particles is to enhance the luminous efficiency. Besides the penetration model mentioned above, there are two other ways to enhance the light output of phosphor layers by CL. The first way is well described in the literature and is based on increasing the conductivity of phosphor layers. The charging of insulating phosphor layers is thought to be detrimental for a number of reasons. In most circumstances it is likely to charge negatively and this will result in the deceleration of the beam before it strikes the phosphor. The field may also cause beam deflection, and may alter the transport of electrons within the phosphor layer. It may also establish fields inside the phosphor grains that impede the recombination of electrons and holes, resulting in a higher proportion of the energy being lost via non-radiative de-excitation routes.

At anode voltages $>7 \mathrm{kV}$ the application of aluminum (Al) backing layers is beneficial: preventing charging of the phosphor layer and enhancing the light output of the screen by reflection of the excited light directed to the vacuum side of the screen. At low anode voltages, however, an Al backing layer cannot be used, because too much of the electron beam is dissipated inside the metallic layer. In this case an alternative method of minimizing charging must be used and one approach is the mixing of the luminescent powder with $\operatorname{In}_{2} \mathrm{O}_{3}$ powder, which is sufficiently conductive and does not absorb light at wavelengths $>430 \mathrm{~nm}^{6-9}$ At first sight it might reasonably be expected that diluting the phosphor layer with non-luminescent material would reduce the efficiency of the layer. It appears, however, that the effects of charging are very strong and, for example, Yang and Yokoyama ${ }^{7}$ found that the $\mathrm{CL}$ of $\mathrm{ZnGa}_{2} \mathrm{O}_{4}$ powder could be enhanced by a factor of 4.2 by mixing with $12 \% \mathrm{In}_{2} \mathrm{O}_{3}$ powder. $\mathrm{Xu}$ et al. ${ }^{8}$ found that the CL intensity of $\mathrm{Lu}_{3} \mathrm{Ga}_{5} \mathrm{O}_{12}$ : $\mathrm{Tb}$ increased by almost a factor of 2 by mixing the luminescent powder with $5 \% \mathrm{In}_{2} \mathrm{O}_{3}$ nanoparticles. Hu et al. ${ }^{9}$ coated $\mathrm{Y}_{2} \mathrm{O}_{3}:$ Eu particles with $\mathrm{In}_{2} \mathrm{O}_{3}$ and measured an increase of the light output by a factor of 1.5 .

One way of avoiding the losses caused by dilution is to use a conductive component that itself contributes to the luminescence (i.e. a conductive phosphor). In making double layers of (slightly) conductive $\mathrm{ZnO}: \mathrm{Zn}$ and non-conductive $\mathrm{Y}_{2} \mathrm{O}_{3}: \mathrm{Eu}$, the situation is more complicated, since both the penetration and the conductivity models for the enhancement of the light output have to be taken into account. This complication is an important issue and will be considered in discussing our measurement results. Since the $\mathrm{Y}_{2} \mathrm{O}_{3}$ :Eu material used in this work consisted of nanosized powders, the deposition of powder layers by settling takes a long time and fabricating mixed layers is impossible due to segregation of $\mathrm{ZnO}: \mathrm{Zn}$ and $\mathrm{Y}_{2} \mathrm{O}_{3}: \mathrm{Eu}$. Therefore micrometer sized $\mathrm{Y}_{2} \mathrm{O}_{2} \mathrm{~S}$ :Eu was included in this study.

The second alternative to enhance the light output is making mixed layers of a CL and photoluminescent (PL) phosphor, in which the near UV or deep blue light of the CL component is used to excite the PL phosphor. This principle was demonstrated by Jung and Han ${ }^{10}$ for $\mathrm{Y}_{2} \mathrm{SiO}_{5}: \mathrm{Ce}$, a CL phosphor that emits in the near UV/deep blue region, and $\mathrm{BaMgAl}_{10} \mathrm{O}_{17}: \mathrm{Eu}$, being a well-known blue emitting PL phosphor.

Results and a discussion thereof are presented in the subsequent section. The final section contains the conclusions. 


\section{Materials and Methods}

Materials.- Micrometer sized ZnO:Zn phosphor was obtained from Kasei Optonix, Japan and used without further treatment. The particle size of the $\mathrm{ZnO}: \mathrm{Zn}$ ranged from 0.2 to $1.5 \mu \mathrm{m}$. Nanometer sized spherical $\mathrm{Y}_{2} \mathrm{O}_{3}: \mathrm{Eu}(2.0 \mathrm{~mol} \%)$ was synthesized in-house, the synthesis has been described in detail previously, ${ }^{5}$ the sample used in this work was a mixture of various monosized batches of equal weights, with particle sizes ranging from 100 to $500 \mathrm{~nm}$. Micrometer sized $\mathrm{Y}_{2} \mathrm{O}_{2} \mathrm{~S}$ :Eu with a particle size of 0.4 to $4.5 \mu \mathrm{m}$ (average $2 \mu \mathrm{m}$ ) was obtained from Phosphor Technology Ltd., and also used without further treatment. Glass substrates coated with one ITO film $(85 \Omega / \mathrm{sq})$ were obtained from Visiontek Ltd., UK, which were cut into square slides of $1 \mathrm{~cm}^{2}$.

Characterization. - The morphology and initial particle size assessment of the phosphor powders were undertaken using a field emission scanning electron microscope (FESEM), Supra 35 VP, Zeiss, Germany.

Phosphor layers were deposited onto the ITO-coated glass slides by settling from iso-propanol suspensions containing various phosphor concentrations. These suspensions were dispersed by ultrasonic cavitation prior to settling. Electrophoretically deposited layers were not studied, since these layers have large internal voids as observed by FESEM studies and are therefore strongly light-scattering. ${ }^{1}$

The CL measurements were carried out in two different high vacuum chambers at a vacuum level of $4 \times 10^{-6}$ mbar using Kimball Physics Inc. (USA) electron guns and associated power supplies over the ranges of electron beam voltages of $1-5 \mathrm{kV}$ and $2-15 \mathrm{kV}$ respectively. The electron guns have the ability to focus and defocus the beam over a range of current densities. Deflection plates enable optimum positioning of the electron beam on sample and reference, the latter is called 'target' in our study. The vacuum chamber, electron gun set-up and viewing port geometries are shown in Fig. 1. The sample was positioned in the center of the vacuum chamber and its position and azimuth angle could easily be changed and optimized. The spectroradiometers shown in Fig. 1 were Spectrobos 1200 instruments manufactured by JETI (Germany), which recorded the spectral radiance of the sample between 380 and $780 \mathrm{~nm}$. From the spectral radiance, the radiance, luminance and CIE-1931 color coordinates are calculated in the usual way using the software package supplied with the instruments.

The measuring method for CL of insulating and slightly conductive phosphor layers has been described in detail previously. ${ }^{5}$ Essential to the method described herein is measuring the excited light in both reflection and transmission mode. In the reflection mode, the CL is measured at the gun side of the sample, whilst in the transmission mode the luminescence transmitted through the ITO-coated glass slide is measured. The advantage of this measuring method is that the sum of the radiances in the reflection and transmission modes is largely inde-

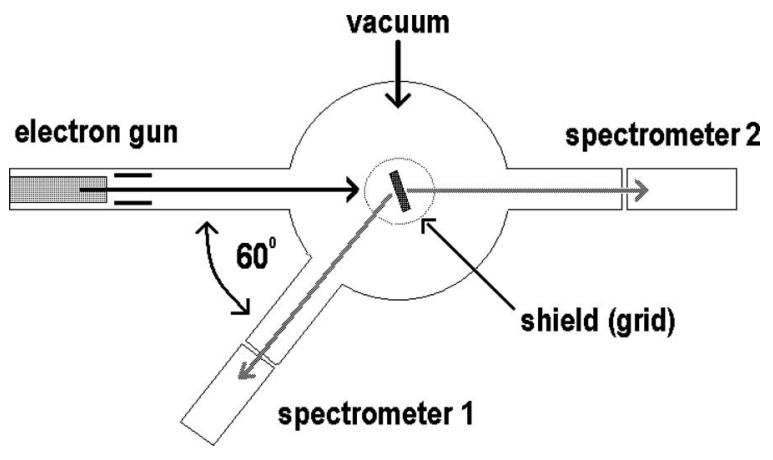

Figure 1. View of vacuum chamber, electron gun, sample, shield, spectrometer 1 (reflection mode) and spectrometer 2 (transmission mode). For the $1-5 \mathrm{kV}$ rig the sample is vertically oriented, whilst for the $2-15 \mathrm{kV}$ system the sample is oriented horizontally.

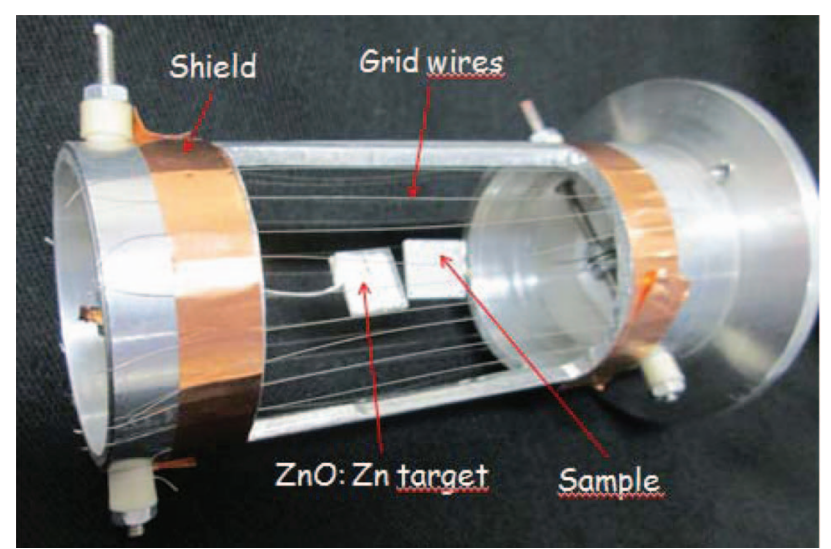

Figure 2. Picture of sample holder with electrical shield and positioning of sample and target.

pendent of the coating weight for non-absorbing samples as we have shown previously. ${ }^{5}$ Another advantage is the opportunity to study the differences in radiance, luminance and color coordinates between the $\mathrm{R}$ - and T-modes in the case of double and multi layers. Radiance and luminance were measured with defocused electron beams, generating a uniform illumination of the phosphor layer. The uniformity of the excitation was checked using a Minolta LS110 luminance meter.

Figure 2 shows a picture of the sample and target holder. The target is an ITO-coated glass slide of $1 \mathrm{~cm}^{2}$ coated with a conductive phosphor layer, $\mathrm{ZnO}: \mathrm{Zn}$ in our case. The problem with measuring the current striking an insulating object is that it charges up under the beam and this makes accurate measurement of the current on the sample very difficult. To avoid these problems the approach used herein was to measure the current in the beam using a conductive target and then the electron beam is directed onto the sample slide, either by changing the deflection conditions of the beam or by moving the sample-target holder. ${ }^{5}$ The current adjustment is kept constant during this change: in this way we ensure that the current density on the sample is the same in every measurement. From the secondary yield curves of various layers of $\mathrm{Y}_{2} \mathrm{O}_{3}: \mathrm{Eu}^{5}$ it was concluded that the charging of our samples is limited to only a few tens of volts so that hardly any primary electrons were deflected at $\mathrm{V}_{\mathrm{A}}>3 \mathrm{kV}$. Furthermore, given that the dielectric breakdown field in a thin crystalline layer of $\mathrm{Y}_{2} \mathrm{O}_{3}$, was measured to be about $20 \mathrm{MV} / \mathrm{m},{ }^{11}$ the maximum charging voltage of the $\mathrm{Y}_{2} \mathrm{O}_{3}:$ Eu layer is expected to be $\sim 40 \mathrm{~V}$ at a thickness of $2 \mu \mathrm{m}$. In a high surface area powder layer, as used here, this figure is probably lower because the threshold for surface breakdown is usually lower than for bulk material.

These considerations suggest that the comparison measuring method may be successfully applied, since the charging voltages are limited and any beam deceleration/deflection will be negligible. Moreover, it is still possible to suppress SE emission successfully.

The angle of incidence of the electron beam on the target and sample is about $30^{\circ}$ as can be derived from Fig. 1. The CL in the reflection and transmission modes measured by spectrometers 1 and 2 respectively was also measured at an angle of $30^{\circ}$ with respect to the normal of the sample surface. At this angle of incidence the reflectivity of the ITO covered glass (front and rear side together) at $555 \mathrm{~nm}$ is $11 \%$. This reflectivity was taken into account together with the reflection losses at the vacuum windows for calculating the efficiency of the CL. Figure 2 also shows the grid wires of the shield, which was biased at $-50 \mathrm{~V}$ to suppress secondary electron emission from the (earthed) sample and target, so that accurate current readings could be taken. The optical transmission of the grid wires is about $98 \%$.

The current striking the target/sample is determined by measuring the voltage drop across a resistor that is placed between the target and earth. A relatively low resistance of $100 \mathrm{k} \Omega$ is used so that with a current of $1 \mu \mathrm{A}$ this yields a voltage on the target of only $0.1 \mathrm{~V}$, which 
may be neglected. Thus the target and sample are basically at earth potential and the kinetic energy of the electrons hitting the sample is equal to the adjusted anode voltage of the power supply.

Calculation of the energy and luminous efficiency.- The calculation of the energy and luminous efficiency of phosphor layers on ITO coated glass has been dealt with in our previous publication. ${ }^{5}$ Spectrometers 1 and 2 measure the spectral radiance from which the radiance is derived by integrating between 380 and $780 \mathrm{~nm}$, while the luminance is indicated after convoluting the spectral radiance with the photopic eye sensitivity curve. When $R_{r}$ is the radiance indicated by spectrometer 1 (reflection) and $R_{t}$ is the radiance indicated by spectrometer 2 (transmission), then the total radiance $R_{a}$ generated in the phosphor layer is:

$$
R_{a}=1.2 R_{r}+1.23 R_{t}
$$

where the coefficient 1.2 is the correction for the reflection losses at the vacuum window in the reflection branch plus an additional X-ray absorbing filter and 1.23 is the correction for the reflection losses in the transmission branch: $11 \%$ for the ITO-coated glass plus about $10 \%$ for the vacuum window. The $2 \%$ shadowing effect of the shield wires, indicated in Fig. 2, is included in these correction coefficients. In our previous work ${ }^{5}$ we have shown that $R_{r}$ is always larger than $R_{t}$, especially for thick layers, in which scattering becomes dominant.

If the light distribution of the $\mathrm{CL}$ in the reflection and transmission modes is Lambertian, the energy efficiency $\eta_{e}$ (in \%) of the luminescence can be written as

$$
\eta_{e}=\frac{100 \pi R_{a}}{j V}
$$

where $j$ is the current density, mostly $1 \mu \mathrm{A} / \mathrm{cm}^{2}$, and $V$ is the anode voltage of the electron beam. The corresponding equation for the luminous efficiency $\eta_{l}$ (in $\mathrm{lm} / \mathrm{w}$ ) is given by:

$$
\eta_{l}=\frac{\pi\left(1.2 L_{r}+1.23 L_{t}\right)}{j V}
$$

where $L_{r}$ and $L_{t}$ are the luminances in the reflection and transmission branch respectively.

\section{Electron Penetration}

Many scientists in the last century have described the penetration of electrons in solids. ${ }^{12-19}$ The electron penetration depth $P$ is generally written as:

$$
P=b V_{A}{ }^{n}
$$

where $V_{A}$ is the electron energy, which will be indicated in this paper as anode voltage, represented in kilovolts; $b$ is a constant that depends on material properties of the solid, such as density $\rho$, atomic number $Z$ and atomic weight $A$. Most authors considered the exponent $n$ to be independent of the material; however, there is no agreement on this approach. It is not always clear in the papers cited above what is exactly meant with "range": the average range of the electrons or the maximum penetration depth.

In most cases the constants $\mathrm{b}$ and $\mathrm{n}$ were fitted to experimental data; nevertheless, the electron ranges according to Whiddington ${ }^{13}$ and Mahkov ${ }^{18}$ differ by more than a factor of 3 at $5 \mathrm{kV}$ and about a factor of 5 at $15 \mathrm{kV}$. Furthermore, the algorithms of Feldman ${ }^{16}$ and Everhard and $\mathrm{Hoff}^{17}$ for the multi-atom compounds $\mathrm{Y}_{2} \mathrm{O}_{3}: \mathrm{Eu}$ and $\mathrm{Y}_{2} \mathrm{O}_{2} \mathrm{~S}: \mathrm{Eu}$ lead to strange deviations when compared to $\mathrm{ZnO}: \mathrm{Zn}$, because the concepts of atomic number $Z$ and atomic mass $A$ lead to ambiguities in multi-atom compounds. We have applied Kanaya and Okayama's algorithm ${ }^{19}$ to estimate the electron range in $\mathrm{ZnO}: \mathrm{Zn}$, $\mathrm{Y}_{2} \mathrm{O}_{3}$ :Eu and $\mathrm{Y}_{2} \mathrm{O}_{2} \mathrm{~S}$ :Eu, because they propose a theoretical equation with only one fitting parameter. Moreover, their equation is almost insensitive to the concepts of atomic number and atomic weight and, finally, the range evaluated with their equation is close to the average of the ranges calculated with the algorithms of the other scientists mentioned here. ${ }^{12-18}$

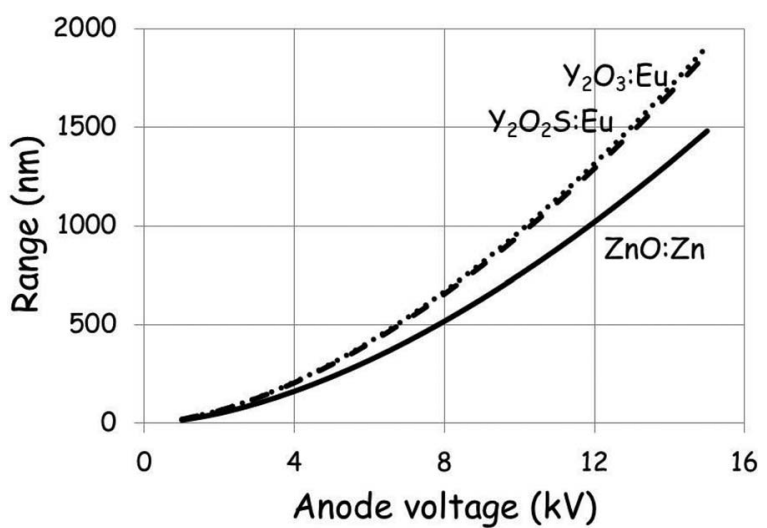

Figure 3. Electron range in crystalline $\mathrm{ZnO}: \mathrm{Zn}, \mathrm{Y}_{2} \mathrm{O}_{3}: \mathrm{Eu}$ and $\mathrm{Y}_{2} \mathrm{O}_{2} \mathrm{~S}: \mathrm{Eu}$ as a function of anode voltage.

Figure 3 depicts the ranges $P$ for crystalline $\mathrm{ZnO}: \mathrm{Zn}, \mathrm{Y}_{2} \mathrm{O}_{3}: \mathrm{Eu}$ and $\mathrm{Y}_{2} \mathrm{O}_{2} \mathrm{~S}$ :Eu as a function of $V_{A}$ : crystalline implies that the densities in constructing Fig. 3 refer to the crystalline phase of the materials. The layer thickness $D$ (in $\mu \mathrm{m}$ ) of a phosphor layer can be expressed as:

$$
D=\frac{10 W}{\rho}
$$

where $W$ is the coating weight (in $\mathrm{mg} / \mathrm{cm}^{2}$ ), $\rho$ is the density of crystalline phosphor material, $5.6 \mathrm{~g} / \mathrm{cm}^{3}$ for $\mathrm{ZnO}: \mathrm{Zn}, 5.0 \mathrm{~g} / \mathrm{cm}^{3}$ for $\mathrm{Y}_{2} \mathrm{O}_{3}: \mathrm{Eu}$ and $4.9 \mathrm{~g} / \mathrm{cm}^{3}$ for $\mathrm{Y}_{2} \mathrm{O}_{2} \mathrm{~S}: \mathrm{Eu}$. The phosphor powder layers deposited by settling exhibit a much lower density than expected (because of a low packing density of about $0.6^{5}$ ). The attenuation of the electron energy only occurs inside phosphor particles and not in the voids between particles; therefore, we may ignore the packing density in discussing the penetration in double layers. Furthermore, the E-beam does not hit the phosphor layers at an angle of incidence of $0^{\circ}$, but rather at $30^{\circ}$, so we shall consider the effective thickness of the phosphor layer, which is $2 / \sqrt{ } 3$ times larger than the value given by Eq. 5 .

\section{Results and Discussion}

Figure 4 is a FESEM image of the $\mathrm{Y}_{2} \mathrm{O}_{2} \mathrm{~S}$ :Eu material used in this work at a magnification of $\times 10000$. Figure 5 presents diagrams of the spectral radiance of $\mathrm{ZnO}: \mathrm{Zn}$ without and with thin top layers of $\mathrm{Y}_{2} \mathrm{O}_{3}: \mathrm{Eu}(5 \mathrm{a})$ and $\mathrm{Y}_{2} \mathrm{O}_{2} \mathrm{~S}: \mathrm{Eu}(5 \mathrm{~b})$ respectively. These spectra have not been corrected for the reflection losses at the various windows as

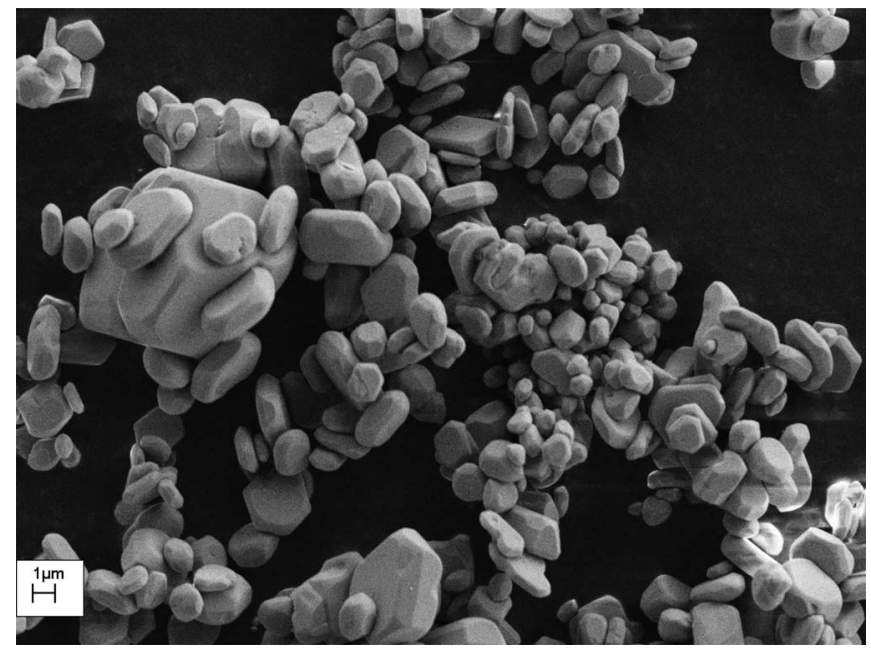

Figure 4. FESEM picture of $\mathrm{Y}_{2} \mathrm{O}_{2} \mathrm{~S}: \mathrm{Eu}$ at a magnification of 10000 . 

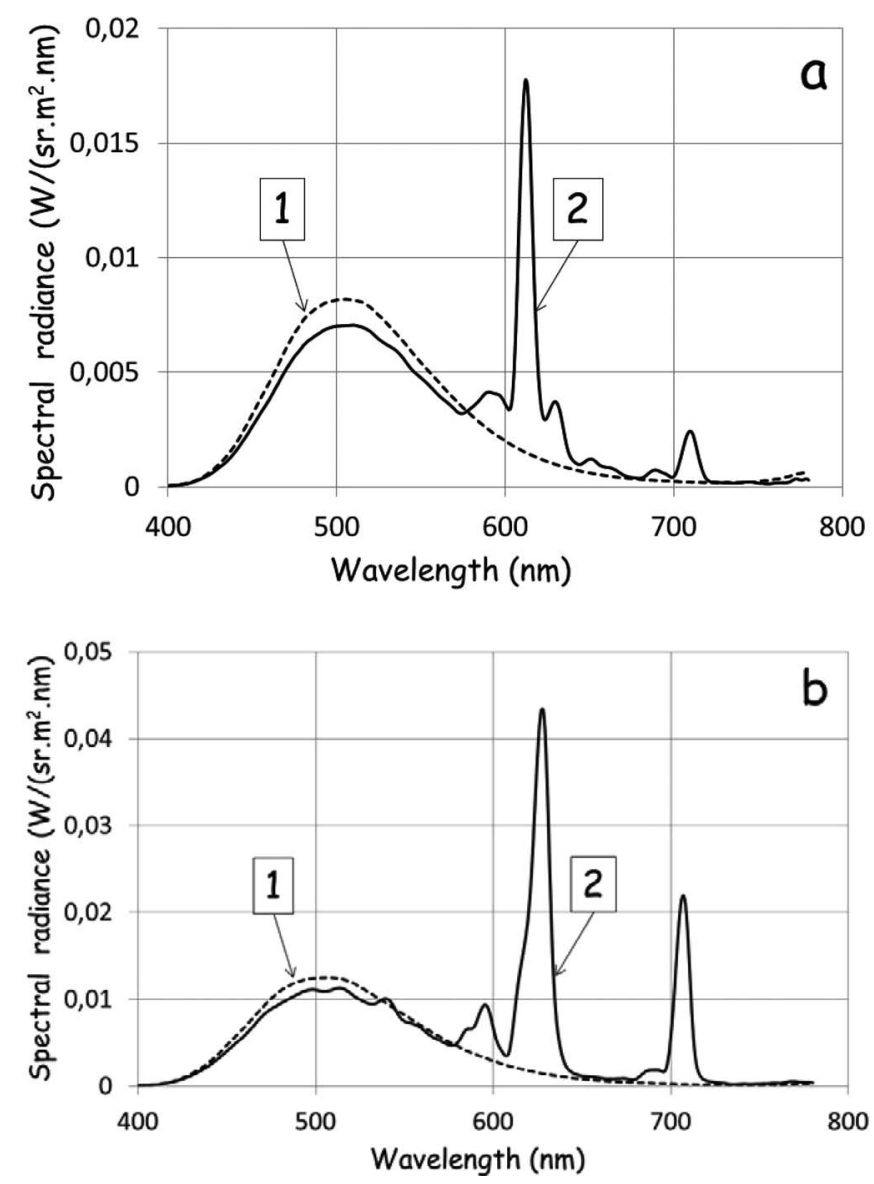

Figure 5. Spectral radiances at $15 \mathrm{kV}$, current density of $1 \mu \mathrm{A} / \mathrm{cm}^{2}$ and shield bias of -50 V. a: $2.2 \mathrm{mg} / \mathrm{cm}^{2} \mathrm{ZnO}: \mathrm{Zn} \mathrm{(1)} \mathrm{and} \mathrm{double} \mathrm{layer} \mathrm{(DL)} \mathrm{of} 2.2 \mathrm{mg} / \mathrm{cm}^{2}$ $\mathrm{ZnO}: \mathrm{Zn}+$ top layer of $0.3 \mathrm{mg} / \mathrm{cm}^{2} \mathrm{Y}_{2} \mathrm{O}_{3}: \mathrm{Eu}$ (2) in transmission mode. b: 2.3 $\mathrm{mg} \mathrm{ZnO}: \mathrm{Zn}(1)$ and double layer (DL) of $2.3 \mathrm{mg} / \mathrm{cm}^{2} \mathrm{ZnO}: \mathrm{Zn}+$ top layer of $0.5 \mathrm{mg} / \mathrm{cm}^{2} \mathrm{Y}_{2} \mathrm{O}_{2} \mathrm{~S}: \mathrm{Eu}(2)$ in reflection mode.

indicated in Eq. 1. Figures 6a and 6b show the energy and luminous efficiency respectively of $\mathrm{ZnO}: \mathrm{Zn}, \mathrm{Y}_{2} \mathrm{O}_{3}: \mathrm{Eu}$ and $\mathrm{Y}_{2} \mathrm{O}_{2} \mathrm{~S}$ : $\mathrm{Eu}$ as a function of anode voltage. The efficiencies of $\mathrm{ZnO}: \mathrm{Zn}$ and $\mathrm{Y}_{2} \mathrm{O}_{2} \mathrm{~S}: \mathrm{Eu}$ do not depend on the coating weight of the phosphor layer; however, in the case of nano-sized $\mathrm{Y}_{2} \mathrm{O}_{3}: \mathrm{Eu}$, there is a slight dependence. The results presented in in Fig. $6 \mathrm{a}$ and $6 \mathrm{~b}$ refer to a coating weight of 1.5 and $2 \mathrm{mg} / \mathrm{cm}^{2} \mathrm{Y}_{2} \mathrm{O}_{3}$ :Eu and explain largely the slightly lower efficiency in comparison to the value published previously, ${ }^{5}$ referring to a coating weight of $1 \mathrm{mg} / \mathrm{cm}^{2}$.

The efficiency of $\mathrm{ZnO}: \mathrm{Zn}$, both energy and lumen based, is almost constant between 1 and $15 \mathrm{kV}$, whereas that of the oxysulfide phosphor increases slightly over the whole voltage range. Between 1 and $5 \mathrm{kV}$ we see strong increase of the efficiency for $\mathrm{Y}_{2} \mathrm{O}_{3}$ : Eu; for this phosphor the efficiency levels off at $\mathrm{V}_{\mathrm{A}}>5 \mathrm{kV}$. A noticeable difference between Fig. $6 \mathrm{a}$ and $6 \mathrm{~b}$ refers to the efficiency of $\mathrm{Y}_{2} \mathrm{O}_{2} \mathrm{~S}: \mathrm{Eu}: \eta_{e}$ of $\mathrm{Y}_{2} \mathrm{O}_{2} \mathrm{~S}: \mathrm{Eu}$ is larger than $\eta_{e}$ of $\mathrm{ZnO}: \mathrm{Zn}$, whereas for $\eta_{l}$ the opposite behavior is seen. This difference can largely be explained by cutting off the emission peak at $707 \mathrm{~nm}$ in the convolution of the spectral radiance with the eye sensitivity curve. The published efficiencies of $\mathrm{ZnO}: \mathrm{Zn}, \mathrm{Y}_{2} \mathrm{O}_{3}: \mathrm{Eu}$ and $\mathrm{Y}_{2} \mathrm{O}_{2} \mathrm{~S}$ :Eu vary widely, ${ }^{6,20-24}$ which makes it difficult to compare our results with earlier publications. Yamamoto ${ }^{24}$ indicates $13 \%$ for the energy efficiency of $\mathrm{Y}_{2} \mathrm{O}_{2} \mathrm{~S}$ : Eu: only slightly higher than our value of $11.5 \%$ at $15 \mathrm{kV}$. Yamamoto's value probably refers to a typical anode voltage of a cathode ray tube (CRT), being $\sim 25 \mathrm{kV}$. He also indicates that the energy efficiency of $\mathrm{Y}_{2} \mathrm{O}_{3}$ :Eu used in CRTs is $8.7 \%$, which is substantially larger than our value of $4.5 \%$ at $15 \mathrm{kV}$. This difference may be explained by (1) charging of the non-conductive $\mathrm{Y}_{2} \mathrm{O}_{3}: \mathrm{Eu}$ particles and/or (2) by difference in grain size: our material consists
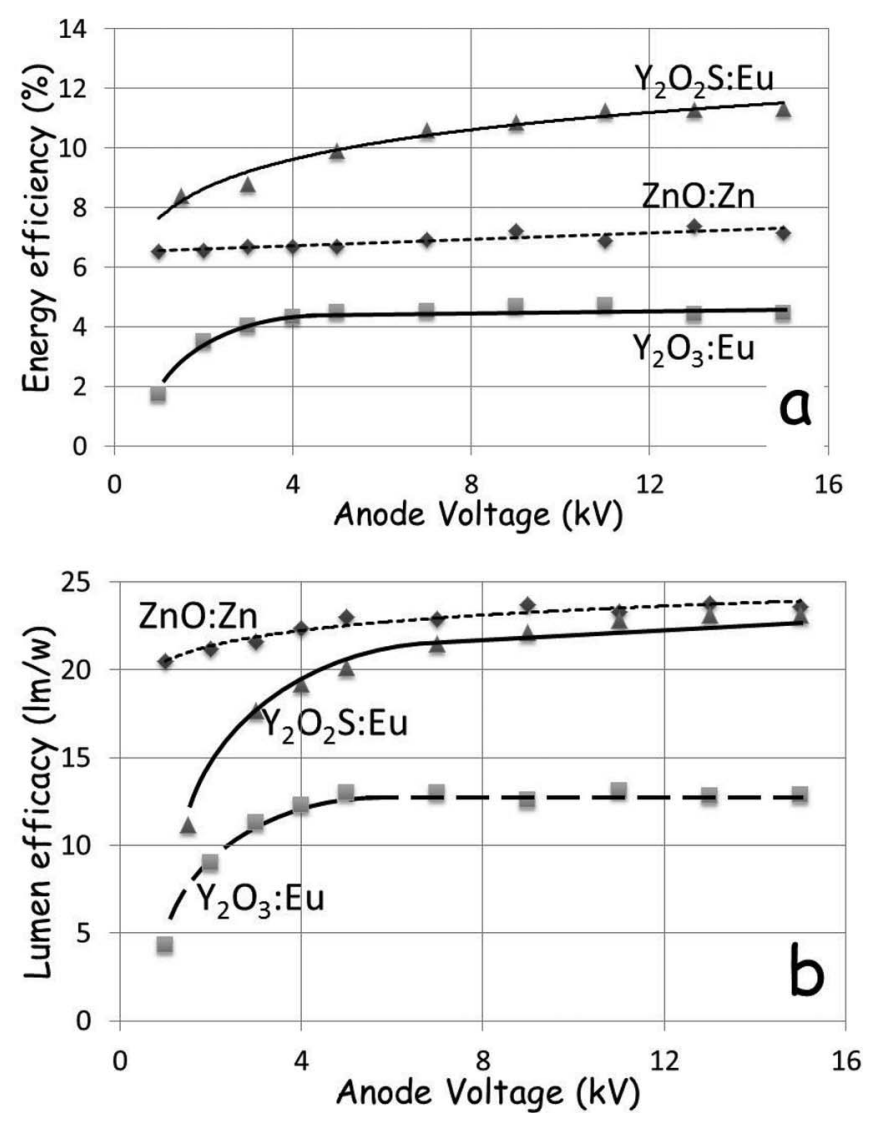

Figure 6. $\mathrm{Cl}$ efficiency of $\mathrm{ZnO}: \mathrm{Zn}$, nanosized $\mathrm{Y}_{2} \mathrm{O}_{3}: \mathrm{Eu}$ and $\mathrm{Y}_{2} \mathrm{O}_{2} \mathrm{~S}: \mathrm{Eu}$ as function of anode voltage at shield bias $-50 \mathrm{~V}$ and current density of $1 \mu \mathrm{A} / \mathrm{cm}^{2}$. a: Energy efficiency. b: Lumen efficacy.

of nanometer sized spherical $\mathrm{Y}_{2} \mathrm{O}_{3}$ :Eu phosphor particles with grain size between 40 and $500 \mathrm{~nm}$, whereas commercial $\mathrm{Y}_{2} \mathrm{O}_{3}$ :Eu largely consists of micrometer sized particles.

Besides the large scattering of the efficiency values of CLphosphors at low anode voltages in the literature, there is no agreement on the shape of the efficiency versus anode voltage curves either. Yang et al. ${ }^{20}$ found a leveling off of the efficiency between 0 and $5 \mathrm{kV}$ for the three phosphors studied here, whereas Shea and Walko ${ }^{23}$ found an almost linear increase of $\eta_{1}$ between 0 and $5 \mathrm{kV}$ for $\mathrm{Y}_{2} \mathrm{O}_{3}: \mathrm{Eu}$. We assume that the inconsistency between the published efficiency values may largely be attributed to different charging conditions of the phosphor layers. Apart from differences in the measuring methods, differences in synthesis will affect the conductivity of the phosphor layers and, thus, the charging conditions as well.

It is tempting to speculate about the low efficiency of the nanosized $\mathrm{Y}_{2} \mathrm{O}_{3}: \mathrm{Eu}$ at anode voltages above $5 \mathrm{kV}$. This material was designed and synthesized to obtain a high efficiency at low anode voltages. ${ }^{25,5}$ At $5 \mathrm{kV}$ the penetration depth of the electrons in $\mathrm{Y}_{2} \mathrm{O}_{3}$ :Eu is about $250 \mathrm{~nm}$, which is slightly less than the average grain size of the material used in our study, being $330 \mathrm{~nm}$. After having excited the first grain, the attenuated primary electron will exit this grain and travel to a second particle in the layer. This process of exciting more than one particle by one electron is thought to be not particularly efficient in the case of charging of the phosphor particles and explains the leveling off of the efficiency of nanosized $\mathrm{Y}_{2} \mathrm{O}_{3}$ :Eu at high anode voltages.

Figure 7 presents the energy efficiency of double layers (DLs) of $\mathrm{ZnO}: \mathrm{Zn}+\mathrm{Y}_{2} \mathrm{O}_{3}: \mathrm{Eu}$ as a function of anode voltage: in Fig. 7a $\mathrm{ZnO}: \mathrm{Zn}$ is overlain by a thin layer of $\mathrm{Y}_{2} \mathrm{O}_{3}:$ Eu while in Fig. $7 b \mathrm{Y}_{2} \mathrm{O}_{3}: \mathrm{Eu}$ is overlain by a thin layer of $\mathrm{ZnO}: \mathrm{Zn}$. The DLs are compared with mixed layers of $\mathrm{ZnO}: \mathrm{Zn}$ and $\mathrm{Y}_{2} \mathrm{O}_{3}: \mathrm{Eu}$ that have the same mass composition. 

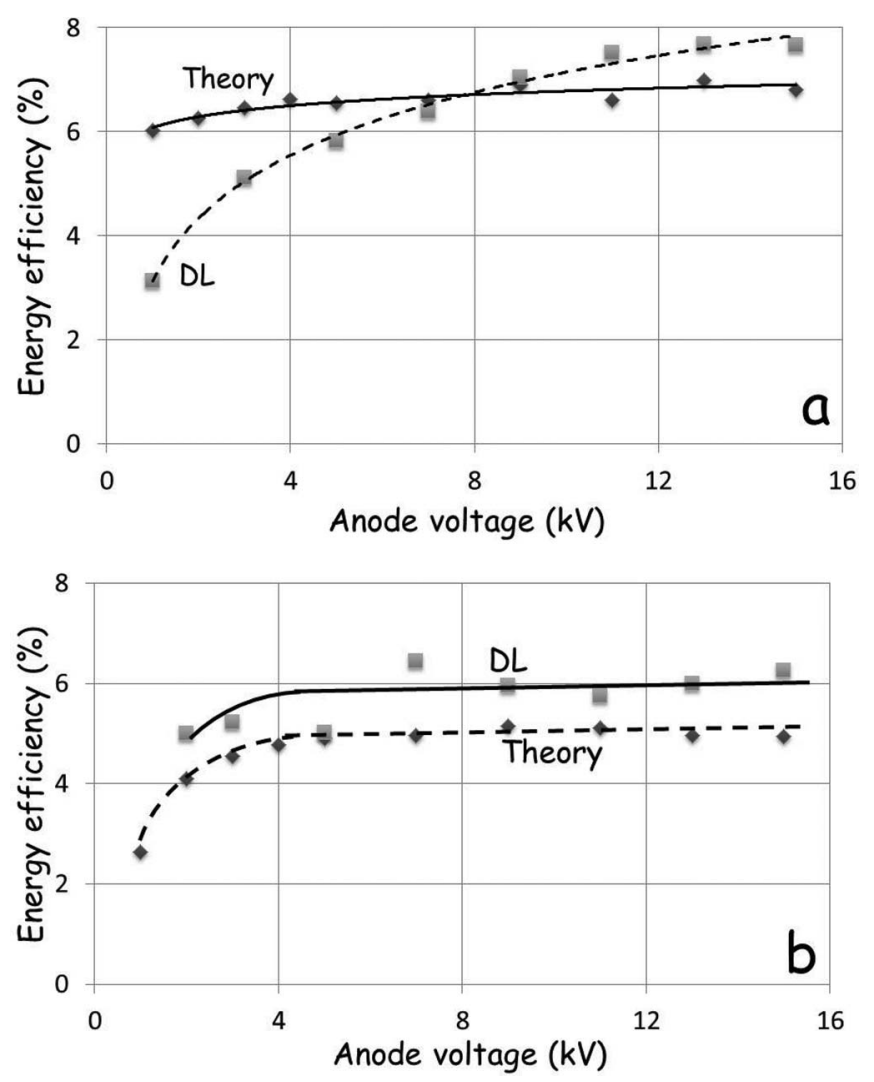

Figure 7. Efficiency of double layers of $\mathrm{ZnO}: \mathrm{Zn}+\mathrm{Y}_{2} \mathrm{O}_{3}: \mathrm{Eu}$ as a function of anode voltage, current density of $1 \mu \mathrm{A} / \mathrm{cm}^{2}$ and shield bias of $-50 \mathrm{~V}$. a: DL (double layer): $2.2 \mathrm{mg} / \mathrm{cm}^{2} \mathrm{ZnO}: \mathrm{Zn}$ overlain by $0.3 \mathrm{mg} / \mathrm{cm}^{2} \mathrm{Y}_{2} \mathrm{O}_{3}: \mathrm{Eu}$. Theory: calculated efficiency of an ideally mixed layer of $2.2 \mathrm{mg} / \mathrm{cm}^{2} \mathrm{ZnO}: \mathrm{Zn}$ and $0.3 \mathrm{mg} / \mathrm{cm}^{2} \mathrm{Y}_{2} \mathrm{O}_{3}:$ Eu. b: DL (double layer): $1.5 \mathrm{mg} / \mathrm{cm}^{2} \mathrm{Y}_{2} \mathrm{O}_{3}$ :Eu overlain by $0.4 \mathrm{mg} / \mathrm{cm}^{2} \mathrm{ZnO}: \mathrm{Zn}$. Theory: calculated efficiency of an ideally mixed layer of $1.5 \mathrm{mg} / \mathrm{cm}^{2} \mathrm{Y}_{2} \mathrm{O}_{3}:$ Eu and $0.4 \mathrm{mg} / \mathrm{cm}^{2} \mathrm{ZnO}: \mathrm{Zn}$.

Unfortunately, it was not possible to prepare mixed layers of $\mathrm{ZnO}: \mathrm{Zn}$ and $\mathrm{Y}_{2} \mathrm{O}_{3}$ :Eu by settling without segregation, because of the difference in particle diameter: the larger $\mathrm{ZnO}: \mathrm{Zn}$ particles settled much faster than the nanosized $\mathrm{Y}_{2} \mathrm{O}_{3}$ :Eu particles. However, the DL-curves should be compared with the curves indicated by "Theory". These latter curves refer to the calculated efficiency of ideally mixed layers of the two phosphors with the same mass composition as the DLs. The theoretical efficiency curves are evaluated as follows:

$$
\eta_{e}^{\text {theory }}=\eta_{e}^{(1)} v^{(1)}+\eta_{e}^{(2)} v^{(2)}
$$

where $\eta_{e}^{(I)}$ and $v^{(I)}$ are the energy efficiency and the volume fraction of $\mathrm{ZnO}: \mathrm{Zn}$ respectively, $\eta_{e}^{(2)}$ and $v^{(2)}$ are the corresponding quantities for $\mathrm{Y}_{2} \mathrm{O}_{3}: \mathrm{Eu}$; furthermore:

$$
v^{(2)}=1-v^{(1)}
$$

The volume fraction is a better quantity to evaluate the weighted average of the efficiency than the molar ratio, because the DLs and mixed layers do not form molecular mixed systems.

Figure 8 shows the $\mathrm{x}$-color coordinate (CIE-1931) of DLs of $\mathrm{ZnO}: \mathrm{Zn}+\mathrm{Y}_{2} \mathrm{O}_{3}: \mathrm{Eu}$ as a function of anode voltage: Fig. 8a refers to the same layers as mentioned in Fig. 7a, while Fig. 8b refers to the same system as in Fig. 7b. The colors in the reflection (R) and transmission ( $\mathrm{T}$ ) modes are different for a DL, both are indicated in the figures. In Fig. 8 the measured $\mathrm{x}$-color coordinates are compared with those of an ideally mixed layer. These theoretical $\mathrm{x}$-color coordinates are evaluated as follows:

$$
x^{\text {theory }}=\frac{\eta_{l}^{(1)} v^{(1)} x^{(1)}+\eta_{l}^{(2)} v^{(2)} x^{(2)}}{\eta_{l}^{(1)} v^{(1)}+\eta_{l}^{(2)} v^{(2)}}
$$
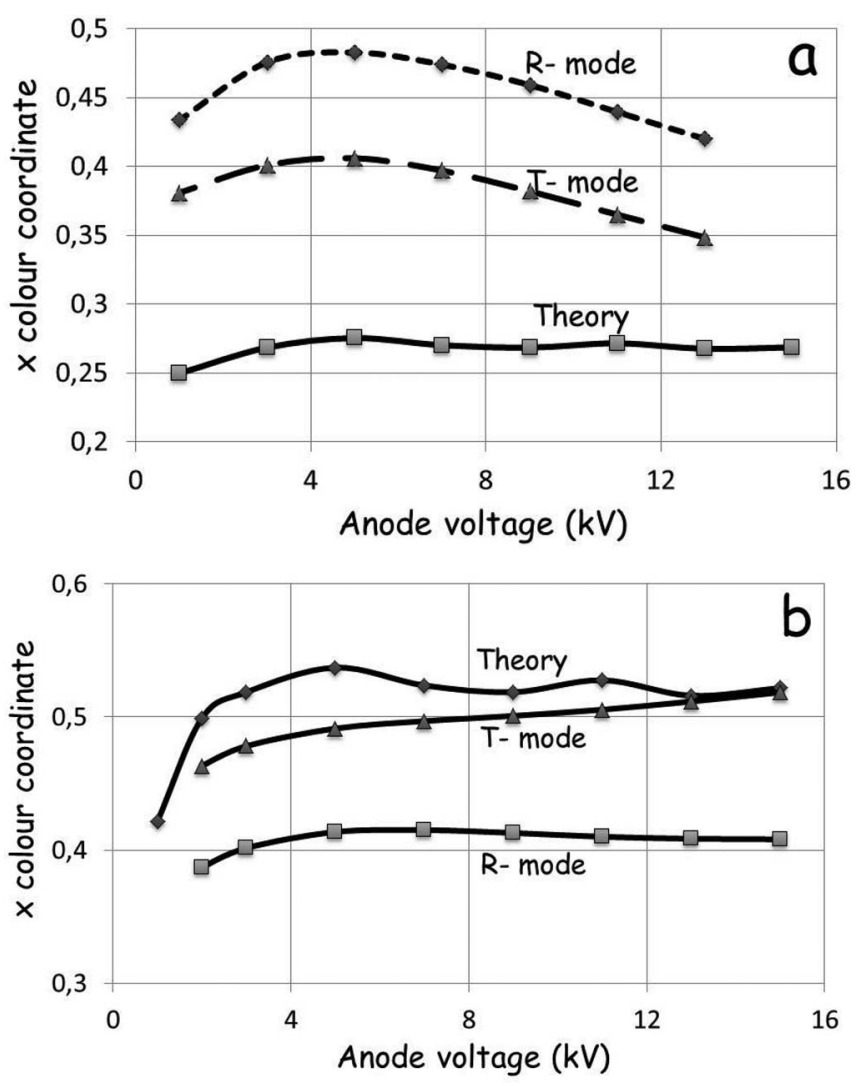

Figure 8. $x$-color coordinate of double layers of $\mathrm{ZnO}: \mathrm{Zn}+\mathrm{Y}_{2} \mathrm{O}_{3}: \mathrm{Eu}$ in reflection and transmission modes as a function of anode voltage, current density of $1 \mu \mathrm{A} / \mathrm{cm}^{2}$ and shield bias of $-50 \mathrm{~V}$. a: R-mode and T-mode of DL: $2.2 \mathrm{mg} / \mathrm{cm}^{2}$ $\mathrm{ZnO}: \mathrm{Zn}$ overlain by $0.3 \mathrm{mg} / \mathrm{cm}^{2} \mathrm{Y}_{2} \mathrm{O}_{3}:$ Eu. Theory: $\mathrm{x}$-color coordinate calculated for an ideally mixed layer of $2.2 \mathrm{mg} / \mathrm{cm}^{2} \mathrm{ZnO}: \mathrm{Zn}$ and $0.3 \mathrm{mg} / \mathrm{cm}^{2}$ $\mathrm{Y}_{2} \mathrm{O}_{3}$ :Eu. b: R-mode and T-mode of DL: $1.5 \mathrm{mg} / \mathrm{cm}^{2} \mathrm{Y}_{2} \mathrm{O}_{3}$ :Eu overlain by $0.4 \mathrm{mg} / \mathrm{cm}^{2} \mathrm{ZnO}: \mathrm{Zn}$. Theory: $\mathrm{x}$-color coordinate calculated for an ideally mixed layer of $1.5 \mathrm{mg} / \mathrm{cm}^{2} \mathrm{Y}_{2} \mathrm{O}_{3}: \mathrm{Eu}$ and $0.4 \mathrm{mg} / \mathrm{cm}^{2} \mathrm{ZnO}: \mathrm{Zn}$.

where $\eta_{l}^{(1)}$ and $x^{(1)}$ are the lumen efficacy and $\mathrm{x}$-color coordinate of $\mathrm{ZnO}: \mathrm{Zn}$ respectively, $\eta_{l}^{(2)}$ and $x^{(2)}$ are the corresponding quantities for $\mathrm{Y}_{2} \mathrm{O}_{3}$ :Eu. Thus, the color coordinate of the ideally mixed layer is obtained by weighing the coordinates of the constituent phosphors with the product of the volume fraction and the lumen efficacy. The color coordinates $(\mathrm{x}, \mathrm{y})$ of $\mathrm{CL}$ of $\mathrm{ZnO}: \mathrm{Zn}$ and $\mathrm{Y}_{2} \mathrm{O}_{3}: \mathrm{Eu}$ are $(0.238$, $0.418)$ and $(0.645,0.348)$ respectively. Because of the large difference in $\mathrm{x}$-color coordinate $(0.407)$, we limit the considerations on color to the $\mathrm{x}$-color coordinate only.

First of all the thin $\mathrm{Y}_{2} \mathrm{O}_{3}: \mathrm{Eu}$ layer on top of $\mathrm{ZnO}: \mathrm{Zn}$ will be discussed. According to Eq. 5 the effective thickness $\mathrm{D}$ of the $0.3 \mathrm{mg} / \mathrm{cm}^{2} \mathrm{Y}_{2} \mathrm{O}_{3}:$ Eu top layer is $0.6 \mu \mathrm{m}$. From Fig. 3 it can be concluded that electrons will not pass this layer at $5 \mathrm{kV}$; however, at $15 \mathrm{kV}$ attenuated primary electrons will penetrate in the $\mathrm{ZnO}: \mathrm{Zn}$ layer. Figure 7a shows that at low anode voltage the efficiency of a DL is much lower than that of the ideal mixture, whereas at $\mathrm{V}_{\mathrm{A}}>8 \mathrm{kV}$, the DL has a larger efficiency. It may be concluded that the results represented in Fig. $7 \mathrm{a}$ are in line with the penetration model. By depositing a non-conductive layer of $\mathrm{Y}_{2} \mathrm{O}_{3}: \mathrm{Eu}$ on top of $\mathrm{ZnO}: \mathrm{Zn}$ one might expect charging and lowering of the efficiency, also at high anode voltage. Since this is not observed, it can be tentatively concluded that the conduction of the bottom $\mathrm{ZnO}: \mathrm{Zn}$ layer also prevents charging of the $\mathrm{Y}_{2} \mathrm{O}_{3}$ :Eu top layer. In other words, thanks to this discharging effect, enhancement of the efficiency by penetration is observed.

Since the layers comprise of phosphor particles, there are many pin holes in the layers, which implies that some non-attenuated primary electrons will hit the $\mathrm{ZnO}: \mathrm{Zn}$ layer. This induces a background excitation of $\mathrm{ZnO}: \mathrm{Zn}$ at low and high anode voltages. Figure 8 a shows 


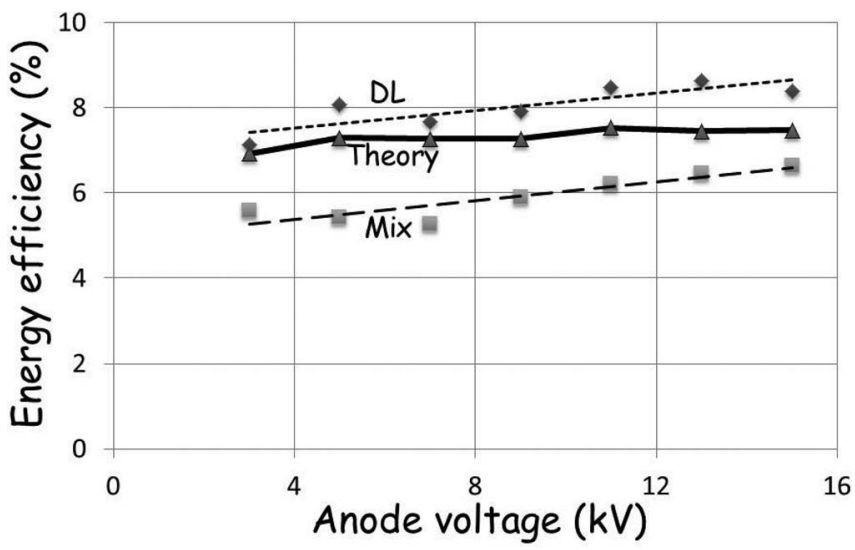

Figure 9. Efficiency of DL and mixed layers of $\mathrm{ZnO}: \mathrm{Zn}+\mathrm{Y}_{2} \mathrm{O}_{2} \mathrm{~S}: \mathrm{Eu}$ as a function of anode voltage, current density of $1 \mu \mathrm{A} / \mathrm{cm}^{2}$ and shield bias of $-50 \mathrm{~V}$. DL: $2.3 \mathrm{mg} / \mathrm{cm}^{2} \mathrm{ZnO}: \mathrm{Zn}$ overlain by $0.5 \mathrm{mg} / \mathrm{cm}^{2} \mathrm{Y}_{2} \mathrm{O}_{2} \mathrm{~S}: \mathrm{Eu}$. Theory: calculated efficiency of ideally mixed layer of $2.3 \mathrm{mg} / \mathrm{cm}^{2} \mathrm{ZnO}: \mathrm{Zn}$ and $0.5 \mathrm{mg} / \mathrm{cm}^{2} \mathrm{Y}_{2} \mathrm{O}_{2} \mathrm{~S}:$ Eu. Mix: measured efficiency of mixed layer of $2.3 \mathrm{mg} / \mathrm{cm}^{2}$ $\mathrm{ZnO}: \mathrm{Zn}$ and $0.5 \mathrm{mg} / \mathrm{cm}^{2} \mathrm{Y}_{2} \mathrm{O}_{2} \mathrm{~S}: \mathrm{Eu}$.

that both the R- and T-mode yield a more red-shifted emission than the ideally mixed layer. The $\mathrm{x}$-color coordinate shows a maximum value a $5 \mathrm{kV}$, which can be understood because of the strong increase of the efficiency of $\mathrm{Y}_{2} \mathrm{O}_{3}:$ Eu between 0 and $5 \mathrm{kV}$. At $\mathrm{V}_{\mathrm{A}}>5 \mathrm{kV}$ a larger fraction of electrons pass the $\mathrm{Y}_{2} \mathrm{O}_{3}$ :Eu-layer and excite $\mathrm{ZnO}: \mathrm{Zn}$, increasing the green component of the luminescence. The $\mathrm{R}$-mode yields a more red-shifted light than the T-mode, which is to be expected with a top layer of $\mathrm{Y}_{2} \mathrm{O}_{3}: \mathrm{Eu}$.

From Figs $7 \mathrm{~b}$ and $8 \mathrm{~b}$ that refer to a thin layer of $\mathrm{ZnO}: \mathrm{Zn}$ on top of $\mathrm{Y}_{2} \mathrm{O}_{3}: \mathrm{Eu}$, the effective thickness of this top layer according to Eq. 5 is $0.9 \mu \mathrm{m}$, allowing primary electrons of $15 \mathrm{kV}$ to pass and to penetrate into the bottom $\mathrm{Y}_{2} \mathrm{O}_{3}$ :Eu layer according to Fig. 3. It is shown over the whole $V_{A}$-range that the efficiency of the DL is substantially larger than that of an ideally mixed layer and that the efficiency is leveling off at $\mathrm{V}_{\mathrm{A}}>5 \mathrm{kV}$. This is not what the penetration model predicts: in that model it would be expected that the efficiency of the DL would be large at $V_{A}<5 \mathrm{kV}$, whereas at $V_{A}>5 \mathrm{kV}$ when a larger fraction of electrons can excite $\mathrm{Y}_{2} \mathrm{O}_{3}: E u$, the efficiency should decrease and the color should become more reddish. The results presented in Figs $7 \mathrm{~b}$ and $8 \mathrm{~b}$ can be explained better in terms of the conductivity model, in which the conductive $\mathrm{ZnO}: \mathrm{Zn}$ top layer is decreasing the negative charging of the $\mathrm{Y}_{2} \mathrm{O}_{3}:$ Eu particles in the same way as the effect of $\mathrm{In}_{2} \mathrm{O}_{3}$ particles. ${ }^{6,8}$

Figs. 9 and 10 present the results of CL measurements of a DL of $0.5 \mathrm{mg} / \mathrm{cm}^{2} \mathrm{Y}_{2} \mathrm{O}_{2} \mathrm{~S}: \mathrm{Eu}$ on top of $\mathrm{ZnO}: \mathrm{Zn}$ and a mixed layer of these phosphors with the same mass composition. The curves indicated with "Theory" refer to calculations of the efficiency and x-color coordinate of a virtual layer, as indicated by Eqs. 6 and 8 respectively. The effective thickness of the $\mathrm{Y}_{2} \mathrm{O}_{2} \mathrm{~S}: \mathrm{Eu}$ top layer is $1.2 \mu \mathrm{m}$, which is less than the average particle size of $2 \mu \mathrm{m}$. This implies that the $\mathrm{Y}_{2} \mathrm{O}_{2} \mathrm{~S}$ :Eu layer has many voids: particles with a diameter $>1.7 \mu \mathrm{m}$ will stop the primary electrons at $15 \mathrm{kV}$, while voids enable direct bombardment of $\mathrm{ZnO}: \mathrm{Zn}$ at $15 \mathrm{kV}$. From this simple geometric consideration we conclude that we cannot expect a penetration effect in this DL-structure. Furthermore, the efficiency of $\mathrm{Y}_{2} \mathrm{O}_{2} \mathrm{~S}: \mathrm{Eu}$ is larger than that of $\mathrm{ZnO}: \mathrm{Zn}$ for the studied range of anode voltages; so, we may not expect any improvement due the penetration effect for this system. In the combination $\mathrm{ZnO}: \mathrm{Zn}+\mathrm{Y}_{2} \mathrm{O}_{2} \mathrm{~S}$ :Eu, the latter phosphor is the "low voltage" phosphor in the range $1-5 \mathrm{kV}$, whereas $\mathrm{ZnO}$ is the "high voltage" phosphor with smaller efficiency. The efficiency of the DL is about $30 \%$ larger than that of the mixed layer over the whole $V_{A}$-range. This result cannot be simply understood in term of the conduction model either, since charging is expected to be less in the mixed layer. However, if the conductivity of the bottom $\mathrm{ZnO}: \mathrm{Zn}$ layer also guarantees non-charging of the $\mathrm{Y}_{2} \mathrm{O}_{2} \mathrm{~S}$ :Eu top layer, like in

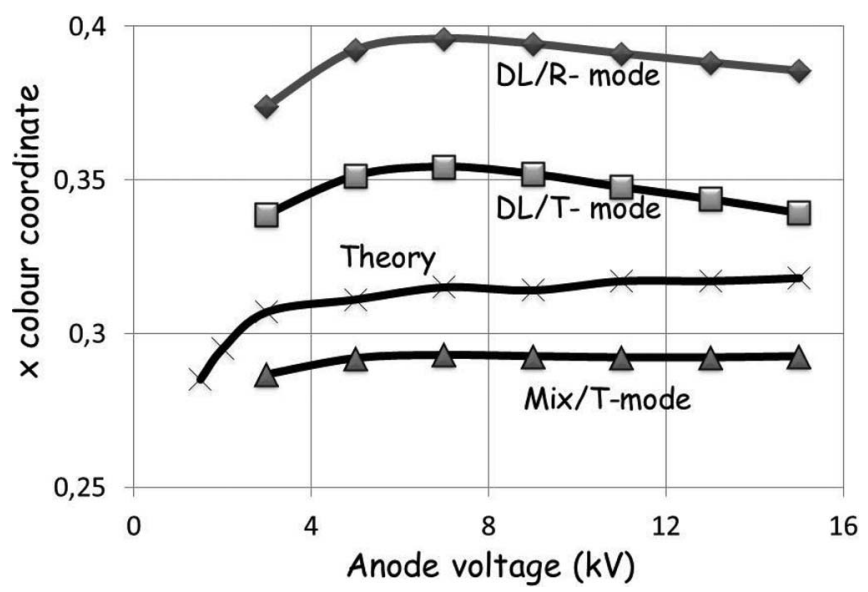

Figure 10. $x$-color coordinate of $\mathrm{DL}$ and mixed layers of $\mathrm{ZnO}: \mathrm{Zn}$ $+\mathrm{Y}_{2} \mathrm{O}_{2} \mathrm{~S}: \mathrm{Eu}$ as a function of anode voltage, current density of $1 \mu \mathrm{A} / \mathrm{cm}^{2}$ and shield bias of $-50 \mathrm{~V}$. DL/R-mode and DL/T-mode: $2.3 \mathrm{mg} / \mathrm{cm}^{2} \mathrm{ZnO}: \mathrm{Zn}$ overlain by $0.5 \mathrm{mg} / \mathrm{cm}^{2} \quad \mathrm{Y}_{2} \mathrm{O}_{2} \mathrm{~S}: \mathrm{Eu}$. Theory: calculated $\mathrm{x}$-color coordinate of ideally mixed layer of $2.3 \mathrm{mg} / \mathrm{cm}^{2} \mathrm{ZnO}: \mathrm{Zn}$ and $0.5 \mathrm{mg} / \mathrm{cm}^{2} \mathrm{Y}_{2} \mathrm{O}_{2} \mathrm{~S}: \mathrm{Eu}$. mix/T-mode: transmission mode of mixed layer of $2.3 \mathrm{mg} / \mathrm{cm}^{2} \mathrm{ZnO}: \mathrm{Zn}$ and $0.5 \mathrm{mg} / \mathrm{cm}^{2} \mathrm{Y}_{2} \mathrm{O}_{2} \mathrm{~S}: \mathrm{Eu}$.

the case of $\mathrm{Y}_{2} \mathrm{O}_{3}: \mathrm{Eu}$ on top of $\mathrm{ZnO}: \mathrm{Zn}$, the results can be understood. In that case, the efficiency of the DL and mixed layers of $\mathrm{Y}_{2} \mathrm{O}_{2} \mathrm{~S}: \mathrm{Eu}$ and $\mathrm{ZnO}: \mathrm{Zn}$ will strongly resemble the behavior of the ideally mixed layer indicated by "Theory": this is in agreement with the experimental observations.

The curves of the $\mathrm{x}$-color coordinate of the mixed layer (T-mode) and the theoretical mixture do not coincide very well. This may be explained by the inaccuracy in adjusting the mass composition of the DL and mixed layers during settling. We estimate that the accuracy of the mass composition of the composite layers is not better than $\pm 5 \%$.

\section{Conclusions}

We have extended CL-measurements of conductive ( $\mathrm{ZnO}: \mathrm{Zn})$ and non-conductive phosphor $\left(\mathrm{Y}_{2} \mathrm{O}_{3}: \mathrm{Eu}\right.$ and $\left.\mathrm{Y}_{2} \mathrm{O}_{2} \mathrm{~S}: \mathrm{Eu}\right)$ layers to high electron beam energies in order to study the electron penetration mechanism. We have found that the CL efficiency of $\mathrm{ZnO}: \mathrm{Zn}$ is constant between 1 and $15 \mathrm{kV}$ and substantially larger than values published in the literature. The efficiency of the nano-sized $\mathrm{Y}_{2} \mathrm{O}_{3}: \mathrm{Eu}$ at $15 \mathrm{kV}$ is lower than that of commercial material measured with an Al backing layer. The efficiency of commercial $\mathrm{Y}_{2} \mathrm{O}_{2} \mathrm{~S}$ :Eu phosphor is almost equal to the published value.

Thin layers of nano-sized $\mathrm{Y}_{2} \mathrm{O}_{3}$ :Eu particles on top of $\mathrm{ZnO}: \mathrm{Zn}$ yield at high anode voltage enhanced CL output, which can be explained in terms of the penetration model. The magnitude of this penetration effect is modest and is about $15 \%$ at an anode voltage of $15 \mathrm{kV}$. For this double layer system we conclude that charging of the insulating top layer is prevented by the conductive bottom layer of $\mathrm{ZnO}: \mathrm{Zn}$. For a thin layer of $\mathrm{ZnO}: \mathrm{Zn}$ on top of $\mathrm{Y}_{2} \mathrm{O}_{3}: \mathrm{Eu}$ we explain the enhanced efficiency in terms of improved conductivity of the layer system. In the case of micrometer-sized $\mathrm{Y}_{2} \mathrm{O}_{2} \mathrm{~S}$ :Eu particles on top of $\mathrm{ZnO}: \mathrm{Zn}$ we cannot detect a penetration effect, because the efficiency of the $\mathrm{Y}_{2} \mathrm{O}_{2} \mathrm{~S}$ :Eu phosphor at low anode voltage is larger than that of $\mathrm{ZnO}: \mathrm{Zn}$

From the results presented here we conclude that the penetration mechanism cannot be applied to enhance the CL efficiency at rather low anode voltages for field emission displays. Furthermore, the grain size of the top layer should not be too large as in the case of $\mathrm{Y}_{2} \mathrm{O}_{2} \mathrm{~S}: \mathrm{Eu}$, in which a DL of $\mathrm{Y}_{2} \mathrm{O}_{2} \mathrm{~S}: \mathrm{Eu}$ and $\mathrm{ZnO}: \mathrm{Zn}$ generate largely the effect of a mixed layer. 


\section{Acknowledgments}

We are grateful to the EPSRC and the Technology Strategy Board(TSB) for funding the PURPOSE (TP11/MFE/6/I/AA129F; EPSRC TS/G000271/1) and CONVERTED (JeS no. TS/1003053/1) programs. We are also grateful to the TSB for funding the CONVERT program.

\section{References}

1. D. den Engelsen, P. G. Harris, T. G. Ireland, R. Withnall, and J. Silver, SID Symposium Digest of Technical Papers, 43, 861 (2012).

2. A. M. Morrell, H. B. Law, E. G. Ramberg, and E. W. Herold, "Color Television Picture Tubes", Academic Press Inc., Orlando (1974), Chapter 8.

3. D. H. Pritchard, "Penetration color screen, color tube, and color television receiver", US patent 3204143 (1965)

4. J. S. Prener and J. D. Kingsley, J. Electrochem. Soc., 119, 1254 (1972).

5. D. den Engelsen, P. G. Harris, T. G. Ireland, R. Withnall, and J. Silver, ECS J. Solid State Sci. Technol., 2, R201 (2013).

6. K. Morimoto and S. Itoh in "Phosphor Handbook", Chapter 8, Edited by W. Yen, S. Shionoya, and H. Yamamoto, 2nd ed., CRC-Press, Boca Raton (2007)

7. S.-H. Yang and M. Yokoyama, J. Electr. Mater, 31, 248 (2002).
8. X. G. Xu, J. Chen, S. Z. Deng, N. S. Xu, and J. Lin, J. Vac. Sci. Technol., 28B, 490 (2010).

9. X. Hu, X. Huang, Y. Hu, and W. Zhuang, J. Rare Earths, 25, 11 (2007).

10. K. Y. Jung and K. H. Han, Electrochem. Solid State Lett., 8, H91 (2005).

11. G. Alacón-Flores, M. Aguilar-Frutis, C. Falcony, M. Garcia-Hipolito, J. J. Araiza-Ibara, and H. J. Herrera-Suárez, J. Vac. Sci. Technol., B24, 1873 (2006).

12. H. A. Bethe, Ann. Physik, 5, 325 (1930).

13. R. Whiddington, Proc. Roy. Soc. (London), A86, 360 (1912).

14. H. M. Terrill, Phys. Rev., 22, 101 (1923).

15. R. O. Lane and D. J. Zaffarano, Phys. Rev., 95, 960 (1954).

16. C. Feldman, Phys. Rev., 117, 455 (1960).

17. T. E. Everhard and P H. Hoff, J. Appl. Phys., 42, 5837 (1971).

18. A. F. Makhov, J. D. Kingsley, and J. S. Prener, J. Appl. Phys., 43, 3073 (1972) and H. Bechtel et al., Philips. J. Res., 50, 433 (1996).

19. K. Kanaya and S. Okayama, J. Phys. D: Appl. Phys., 5, 43 (1971).

20. S. Yang, F. Zhang, C. Stoffers, S. M. Jacobsen, C. J. Summers, P. N. Yocom, and S. McClelland, Proc. SPIE., 2408, 194 (1995).

21. L. E. Shea, Electrochem. Soc. Interface, Summer, 24 (1998).

22. L. E. Shea and R. J. Walko, Proc SPIE, 3636, 105 (1999).

23. G. Wakefield, E. Holland, P. J. Dobson, and J. L. Hutchison, Adv. Mater, 13, 1557 (2001).

24. H. Yamamoto in "Phosphor Handbook", Chapter 2.9, Edited by W. Yen, S. Shionoya, and H. Yamamoto, 2nd ed., CRC-Press, Boca Raton (2007).

25. X. Jing, T. Ireland, C. Gibbons, D. Barber, J. Silver, A. Vecht, G. Fern, P. Trogwa, and D. Morton, J. Electrochem. Soc., 146, 4654 (1999). 